\section{Inhibition of Copper Corrosion in NaCI Solution by Propolis Extract}

\author{
V. Grudić, I. Bošković," and A. Gezović \\ Faculty of Metallurgy and Technology, \\ University of Montenegro, Džordža Vašingtona BB, \\ 81000 Podgorica, Podgorica, Montenegro
}

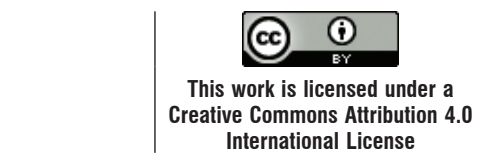

doi: 10.15255/CABEQ.2018.1357

Original scientific paper

Received: April 2, 2018

Accepted: August 3, 2018

This study investigates the possibility of corrosion inhibition of copper by propolis extract in $0.51 \mathrm{~mol} \mathrm{dm}^{-3} \mathrm{NaCl}$ solution. The influence of propolis extract concentration and temperature on corrosion behaviour of copper was studied using electrochemical methods. The protective effect of propolis coating deposited on the electrode surface and dried in air was also examined. The results of the study showed that with increasing propolis extract concentration in the solution there was a slight increase in open circuit copper potential to positive values, an increase in polarization resistance, and a decrease in the corrosion current density. A significantly more prominent change of all three of these parameters was observed in the case of propolis coating. Potentiodynamic measurements indicate that propolis extract acts as a mixed corrosion inhibitor, which is adsorbed on the electrode surface according to Langmuir's isotherm. The decrease in inhibition efficiency with increasing temperature indicates physical adsorption. Adsorption of propolis on the electrode surface was confirmed by the spectrophotometric method.

Keywords:

copper, propolis, corrosion, adsorption

\section{Introduction}

Because of its very good constructional properties, high electrical and thermal conductivity, and its relatively noble properties, copper is widely used in various industries. Research has shown that copper corrodes in chlorine-containing media ${ }^{1-3}$. The corrosive effect of aggressive components in electrolytes in practice can be reduced in many ways, but most often with the use of inhibitors. The use of environmentally harmful chemicals, including many effective corrosion inhibitors, has been reduced drastically in recent years. Therefore, many alternative natural products, eco-friendly or green corrosion inhibitors have been developed ${ }^{4}$. Apart from herbal extracts, honey and propolis are natural products, which can also be used as corrosion inhibitor for metals and alloys. Previous research has shown that ethanol extract of propolis significantly inhibits corrosion of stee $1^{5-7}$ and copper alloys ${ }^{8}$ in sulphate and chloride solutions.

Propolis is a resinous substance, the composition of which depends on vegetation, time, and collection area. The colour of this substance varies from yellow green to dark brown, depending on the source and age. It is accepted that propolis consists of $50 \%$ resin, $30 \%$ bees wax, $10 \%$ essential and

*Corresponding author: Ivana Bošković, E-mail: ivabo@ac.me aromatic oils, $5 \%$ pollen, and $5 \%$ other substances, usually flavonoids ${ }^{9,10}$. In addition, propolis contains minerals, such as iron and zinc, and vitamins A, B1, B2, B6, C, and E. Apart from medical purposes, propolis is also used in industry. It is considered that some organic substances in propolis capable of inhibiting corrosion. Namely, flavonoids are substances with very good antioxidative properties. The following flavonoids have been found in propolis: galangin, quercetin, kempferol, apigenin, pinocembrin, and pinobanksin. All of them contain polyphenol and phenol groups (Scheme 1). Owing to such composition, the inhibition effect of propolis is based on adsorption and formation of a protective layer on the surface of the metal.

The aim of this work was to investigate the inhibition effect of propolis extract as a new and non-toxic inhibitor of copper corrosion in a 0.51 mol dm${ }^{-3} \mathrm{NaCl}$ solution. The experiments were performed by electrochemical methods and UV-VIS spectroscopy.

\section{Experimental}

\section{Materials preparation}

Cylindrical copper samples (purity $99.99 \%$ ) were soldered beforehand to insulated copper wires in order to achieve good electrical contact, and in- 
<smiles>O=c1c(O)c(-c2ccccc2)oc2cc(O)cc(O)c12</smiles>

a) galangin<smiles>O=c1c(O)c(-c2ccc(O)c(O)c2)oc2cc(O)cc(O)c12</smiles>

b) quercetin<smiles>O=c1c(O)c(-c2ccc(O)cc2)oc2cc(O)cc(O)c12</smiles>

c) kempferol<smiles>O=c1cc(-c2ccc(O)cc2)oc2cc(O)cc(O)c12</smiles>

d) apigenin

e) pinocembrin

Scheme 1 - Structural formulas of flavonoids, present in propolis ${ }^{6}$

sulated with polymeric mass (Simgal- R paste) on all sides. The working surface of the electrode was $1 \mathrm{~cm}^{2}$. Before electrochemical measurements, the electrode surface was cleaned mechanically with abrasive sanding papers of fineness 400, 600 and 1200. After that, the surface was washed with ethanol and distilled water.

The electrode with the solid coating of propolis was prepared by applying alcoholic propolis extract to the electrode surface. The obtained coating was air-dried.

The measurements were carried out in an 0.51 mol dm${ }^{-3} \mathrm{NaCl}$ solution, which was prepared by the dissolution of the solid $\mathrm{NaCl}$, p.a. purity, in distilled water.

A commercial alcohol extract of propolis, insoluble in an aqueous $\mathrm{NaCl}$ solution, was used in experimental measurements. Therefore, the calculated amounts of commercial extract were diluted with $30 \mathrm{~cm}^{3}$ of ethanol and added to $200 \mathrm{~cm}^{3}$ of $0.51 \mathrm{~mol} \mathrm{dm}{ }^{-3} \mathrm{NaCl}$ solution. Thus, solutions of different concentrations of commercial propolis extract (350-3500 $\mathrm{mg} \mathrm{dm}^{-3}$ ) were obtained. The solutions were constantly mixed in order to fully dissolve the propolis extract.

\section{Electrochemical experiments}

Potentiostate-Galvanostate 273 analyzer model PAR - 325II interfaced with software was used for the corrosion investigations. Polarization experiments were carried out in a special three-electrode glass cell with a cylindrical graphite counter electrode and a saturated calomel electrode (SCE) as reference.

The time dependence of the open circuit potential for $\mathrm{Cu}$ in $0.51 \mathrm{~mol} \mathrm{dm}^{-3} \mathrm{NaCl}$ solution was measured in duration of 30 minutes at temperature of $25^{\circ} \mathrm{C}$ in solutions with and without the addition of various propolis extract concentrations. Linear polarization method was recorded in the potential range of $\pm 20 \mathrm{mV}$ relative to corrosion potential. Potentiodynamic measurements were performed in the potential range from $-250 \mathrm{mV}$ to $+500 \mathrm{mV}$ relative to open circuit potential, with continuous monitoring of current between the working and counter electrode.

\section{Spectrophotometric measurements}

Adsorption behaviour of organic molecules from propolis was interpreted by spectrophotometric method. UV - VIS spectra of propolis extract solution (concentration of $3500 \mathrm{mg} \mathrm{dm}{ }^{-3}$ in 0.51 mol dm${ }^{-3} \mathrm{NaCl}$ ) were analysed before and after immersion of copper sample in the solution for 48 hours. Recording of the spectrum was performed by the 105 UV-VIS Spectrophotometer BUCK Scientific.

\section{Results and discussion}

\section{Open circuit potential measurements}

The dependence of the open circuit potential for $\mathrm{Cu}$ in $0.51 \mathrm{~mol} \mathrm{dm}^{-3} \mathrm{NaCl}$ solution in the absence and presence of propolis extract as a function of time is shown in Fig. 1.

It can be observed that the changes in the copper corrosion potential with the addition of propolis extract are not significantly expressed in relation to the corrosion potential of $\mathrm{Cu}$ in the non-inhibited solution (Fig. 1). Corrosion potential values shifted to negative values during the first ten minutes of open circuit potential measurements, and then achieved a constant value. This behaviour is at- 


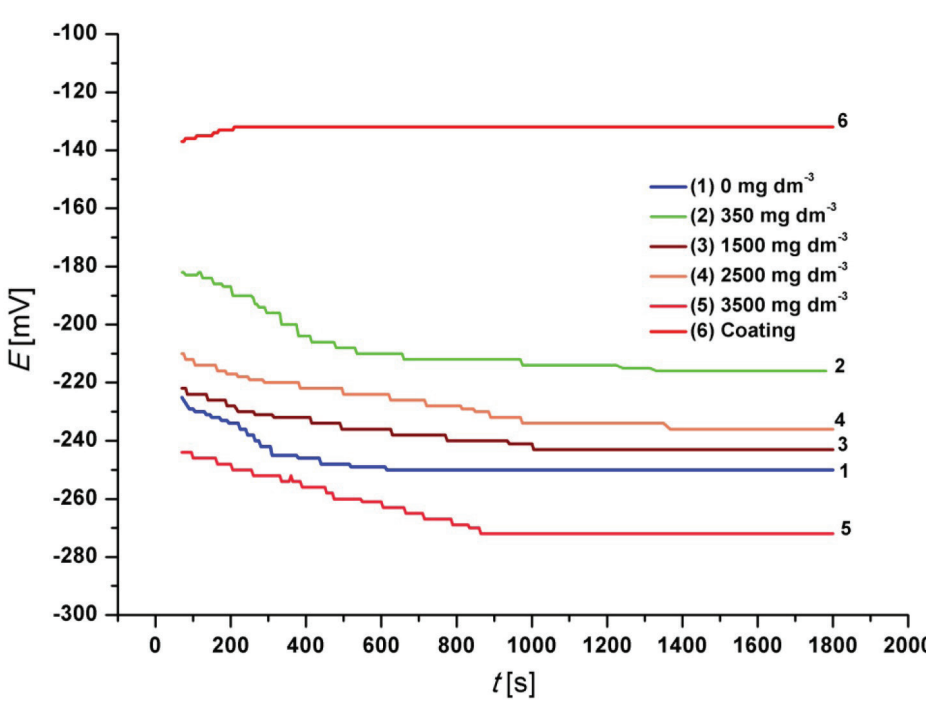

Fig. 1 - Dependence of corrosion potential for $\mathrm{Cu}$ in 0.51 mol $\mathrm{dm}^{-3} \mathrm{NaCl}$ solution in the absence and presence of propolis extract as a function of time

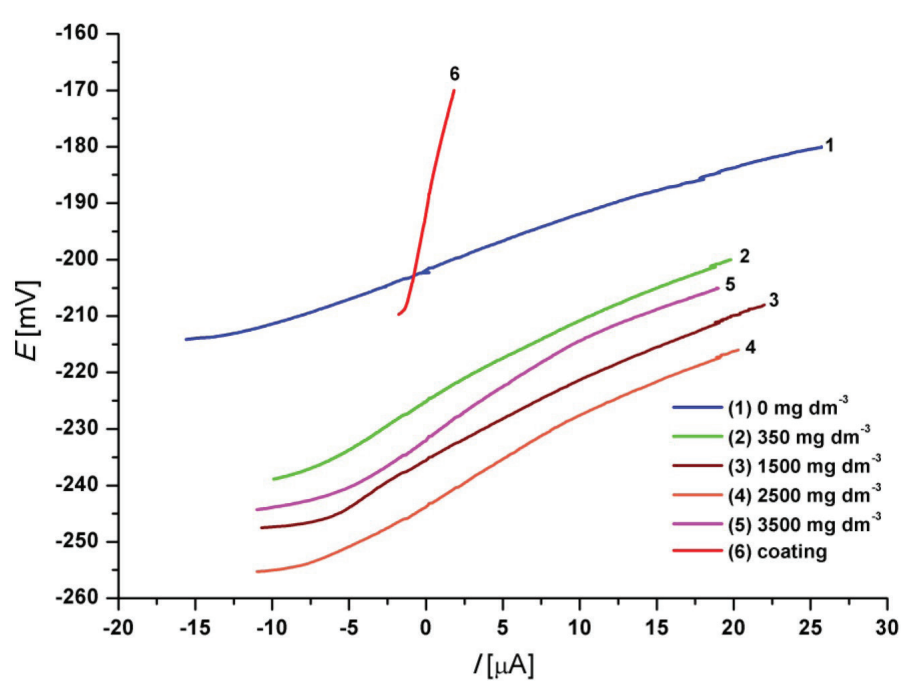

Fig. 2 - Linear polarization curves for copper in $0.51 \mathrm{~mol} \mathrm{dm}^{-3}$ $\mathrm{NaCl}$ solution without stirring as a function of various propolis extract concentrations

tributed to the formation of the adsorbed layer on the copper surface, since there was no protective film to prevent metal dissolution at the moment of electrode immersion in the test solution ${ }^{11}$. In such cases, it is considered that cathode processes are dominant in relation to anode processes ${ }^{12}$. Generally, if the displacement in corrosion potential is higher than $85 \mathrm{mV}$ in the presence of inhibitor with respect to corrosion potential of the blank, the inhibitor can be classified as a cathodic or anodic type $^{13}$. No significant changes in open circuit potentials in chloride solution with propolis extract compared to blank solution suggest a mixed type of inhibitor.

Potential of electrode with propolis coating is much more positive than corrosion potential for the copper in the blank $\mathrm{NaCl}$ solution. This potential slowly shifted towards positive values with time. Such behaviour indicates a predominant inhibition effect of propolis coating.

\section{Polarization measurements}

After 30 minutes of monitoring open circuit potential, polarization resistance was determined by the linear polarization method. Having establishing stable corrosion potential, the working electrode polarized cathodically and anodically $\pm 20 \mathrm{mV}$ relative to the corrosion potential. Linear polarization curves for copper in $0.51 \mathrm{~mol} \mathrm{dm}{ }^{-3} \mathrm{NaCl}$ solution without stirring at $25^{\circ} \mathrm{C}$ as a function of various concentrations of propolis extract are shown in Fig. 2.

The slope of the linear part of the curve increased with increasing propolis extract concentration, indicating an increase in polarization resistance, i.e., increased corrosion resistance of copper. The copper electrode with propolis coating had the highest corrosion resistance (Fig. 2).

Values of polarization resistance were determined from the slope of linear part of the curves. Based on these values, degree of surface coverage $(\theta)$ and inhibition efficiency $(\eta)$ were calculated according to equation (1):

$$
\eta=\theta \cdot 100=\left(\frac{\left(R_{p}\right)_{\mathrm{inh}}-R_{p}}{\left(R_{p}\right)_{\mathrm{inh}}}\right) \cdot 100
$$

where $R_{p}$ and $\left(R_{p}\right)_{\text {inh }}$ are the values of polarization resistance in the absence and presence of inhibitor.

The values of polarization resistance, degree of surface coverage, and inhibition efficiency determined by linear polarization method are shown in Table 1. It is evident that, with increasing propolis concentration, the inhibition efficiency increased, as well as that the highest efficiency was achieved with solid propolis coating.

Table 1 - Linear polarization parameters for copper corrosion in $0.5 \mathrm{M} \mathrm{NaCl}$ in the presence of various concentrations of propolis extract at temperature $25^{\circ} \mathrm{C}$

\begin{tabular}{cccccc}
\hline$C\left[\mathrm{mg} \mathrm{dm}^{-3}\right]$ & $j_{\text {corr }}\left[\mu \mathrm{A} \mathrm{cm}^{-2}\right]$ & $R_{\mathrm{p}}[\mathrm{k} \Omega]$ & $\theta$ & $\eta[\%]$ \\
\hline 0 & 24.53 & 0.885 & - & - \\
350 & 16.17 & 1.341 & 0.3408 & 34.08 \\
1500 & 15.73 & 1.381 & 0.3587 & 35.87 \\
2500 & 14.11 & 1.539 & 0.4248 & 42.48 \\
3500 & 12.37 & 1.756 & 0.5364 & 53.64 \\
coating & 1.875 & 11.58 & 0.9236 & 92.36 \\
\hline
\end{tabular}




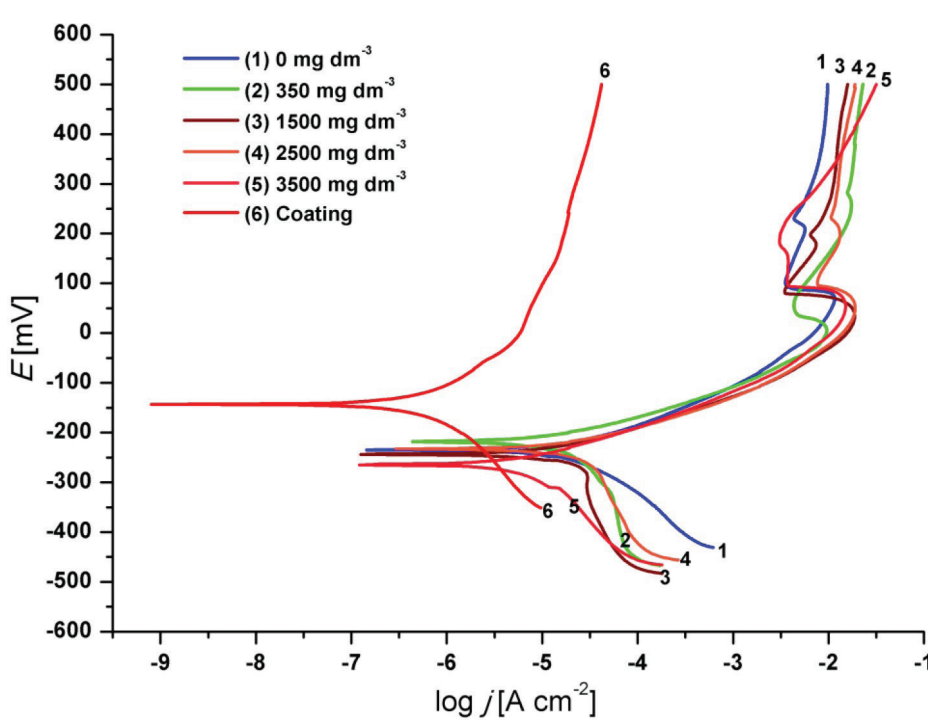

Fig. 3 - Potentiodynamic polarization curves in $0.51 \mathrm{~mol} \mathrm{dm}^{-3}$ $\mathrm{NaCl}$ solution as a function of various propolis extract concentrations

Potentiodynamic polarization curves of copper in $0.51 \mathrm{~mol} \mathrm{dm}^{-3} \mathrm{NaCl}$ solution as a function of various propolis extract concentrations are shown in Fig. 3. Corrosion parameters were determined from the polarization curves, while inhibition efficiency was calculated using equation (2):

$$
\eta=\frac{j_{\text {corr }}^{o}-j_{\text {corr }}}{j_{\text {corr }}^{o}} \cdot 100
$$

where $j_{\text {corr }}$ and $j_{\text {corr }}^{o}$ are the values of corrosion current density with and without inhibitor, respectively.

The addition of propolis extract in $\mathrm{NaCl}$ solution led to a decrease in corrosion current density and displacement of corrosion potential in cathodic and anodic direction. Decrease in the corrosion current density indicates the inhibitory effect of propolis, which is consistent with the data obtained with the previous two methods. The value of the corrosion potential significantly increased, while cathodic and anodic currents decreased for the sample with propolis coating. Considering that the displacement in corrosion potential is not higher than $85 \mathrm{mV}$ in the presence of inhibitor with the respect to corrosion potential of the blank, propolis can be classified as a mixed type of inhibitor with a more pronounced impact on the cathode reaction ${ }^{6,13,14}$.

The inhibition efficiency of propolis extract on copper corrosion in $0.51 \mathrm{~mol} \mathrm{dm}^{-3}$ $\mathrm{NaCl}$ solution increased with increasing propolis extract concentration, reaching a value of $72.69 \%$ at a concentration of $3500 \mathrm{mg} \mathrm{dm}^{-3}$, while the inhibition efficiency of the propolis coating was $98.54 \%$.
The slight change in the value of Tafel's slopes with increasing propolis extract concentration indicates that addition of propolis does not change the copper dissolution mechanism, meaning that propolis exhibits its inhibitory effect only by adsorption on the electrode surface.

\section{Adsorption models}

The process of metal corrosion inhibition is based on the adsorption of organic inhibitor molecules on the metal surface. Adsorption of the organic inhibitor can be physical adsorption or chemisorption. In order to examine the adsorption mechanism closely, it is important to determine the adsorption isotherm that best fits the experimental results. Effective adsorption of organic inhibitors can be considered as a process of substitution, which takes place at the electrode electrolyte boundary phase according to equation ${ }^{15}$ :

$$
\mathrm{Org}_{\text {inh }}+\mathrm{xH}_{2} \mathrm{O}_{\text {(ads) }} \rightleftarrows \operatorname{Org}_{\text {inh }}{ }_{\text {(ads) }}+\mathrm{xH}_{2} \mathrm{O}_{\text {(aq) }}
$$

where $\operatorname{Org}_{\text {inh(ag) }}$ and $\operatorname{Org}_{\text {inh(ads). }}$ are the molecules of organic inhibitors in the solution and molecules adsorbed on the metal surface, respectively. $\mathrm{H}_{2} \mathrm{O}_{\text {(ads) }}$ represents water molecules adsorbed on the metal surface, and $\mathrm{x}$ is the number of water molecules, which is substituted with one molecule of organic inhibitor.

Results of examination showed that adsorption of propolis on the copper surface can be best described by Langmuir's adsorption isotherm (Fig. 4). Langmuir's adsorption isotherm was given by the following equation ${ }^{16}$ :

$$
\frac{C}{\theta}=\frac{1}{K_{\text {ads }}}+C
$$

where $\mathrm{K}_{\text {ads }}-$ is the equilibrium constant of adsorption process; $\theta$ - degree of surface coverage; $C$ - is the inhibitor concentration. Dependence $(C / \theta)$ as a function of $C$ is straight line with the slope equal to the unit and ordinate intercept $-K_{\text {ads }}{ }^{-1}$.

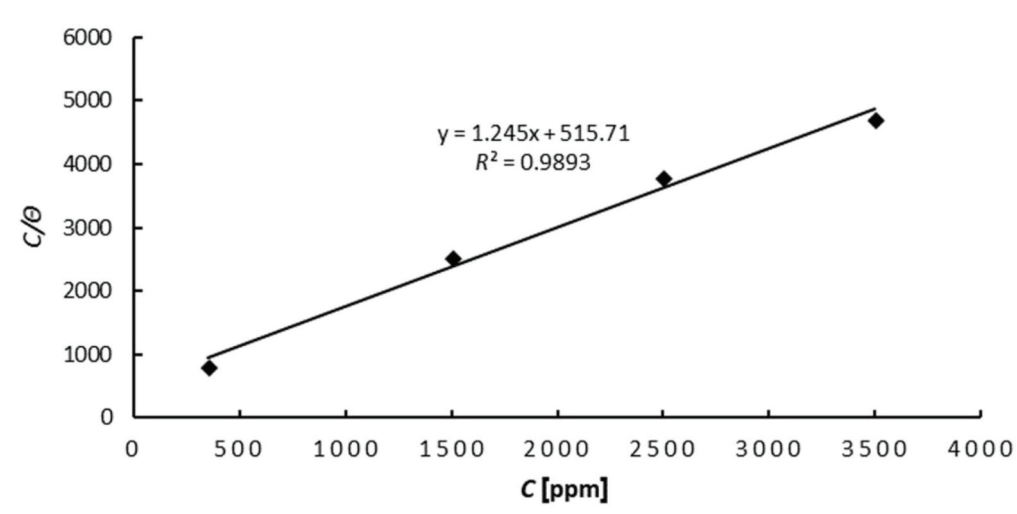

Fig. 4 - Langmuir's adsorption isotherm for propolis adsorption process on the copper surface in $\mathrm{NaCl}$ solution 
High value of $R^{2}$, which amounts 0.9893 , indicates that adsorption process can be described by Langmuir's isotherm ${ }^{6,8}$. Langmuir's isotherm assumes that the solid surface contains a fixed number of adsorption sites, and each site holds one adsorbed species, indicating monolayer adsorption ${ }^{17}$.

On the basis of obtained straight line, the value of adsorption constant $K_{\text {ads }}=1.93 \mathrm{~mol}^{-1} \mathrm{dm}^{3}$ was calculated. The value of the given constant indicates that propolis is easily and strongly adsorbed on the surface of metal ${ }^{18}$.

Equilibrium constant of adsorption process was related to free energy of adsorption by equation ${ }^{19}$ :

$$
K_{\text {ads }}=\frac{1}{55.55} \exp \left(-\frac{\Delta G_{\text {ads }}}{R T}\right)
$$

where $\Delta G_{\text {ads }}-$ Gibbs free energy of adsorption $\left(\mathrm{kJ} \mathrm{mol}^{-1}\right) ; 55.55\left(\mathrm{~mol} \mathrm{dm}^{-3}\right)$ - molar concentration of water in solution.

The value of free Gibss energy of adsorption $\left(\Delta G_{\text {ads }}\right)$ at temperature $25^{\circ} \mathrm{C}$ calculated from equation (5) was $-11.582 \mathrm{~kJ} \mathrm{~mol}^{-1}$. The obtained value $\Delta G_{\text {ads }}$ indicates the spontaneity of adsorption of propolis on the surface of copper electrode ${ }^{20}$, as well as strong physical adsorption ${ }^{5,21}$. Therefore, inhibitory effect of propolis on the surface of copper electrode is the consequence of the formation of a protective film. This film physically blocks attention of aggressive ions from $\mathrm{NaCl}$ solution.
Influence of temperature on copper corrosion in $0.51 \mathrm{~mol} \mathrm{dm}^{-3} \mathrm{NaCl}$ was examined in the temperature range of $25{ }^{\circ} \mathrm{C}-55^{\circ} \mathrm{C}$. The results of examination (Table 2) show that corrosion rate in the uninhibited and in the inhibited $\mathrm{NaCl}$ solution increases with temperature. A quantitative relationship between temperature and corrosion rate is given by Arrhenius's equation ${ }^{22}$ :

$$
j_{\text {corr }}=A \exp \left(\frac{-E_{a}}{R T}\right)
$$

where: $j_{\text {corr }}$ is current density, which is directly proportional to the corrosion rate, $A$ is Arrhenius's pre-exponential factor, $E_{\mathrm{a}}$ is the apparent activation energy, $R$ is the universal gas constant (8.314 $\left.\mathrm{J} \mathrm{K}^{-1} \mathrm{~mol}^{-1}\right), T$ is the absolute temperature $(\mathrm{K})$. Dependence $\ln j_{\text {corr }}=\mathrm{f}(1 / T)$ is given by equation (7):

$$
\ln j_{\text {corr }}=-\frac{E_{a}}{R T}+\ln A
$$

A plot of $\ln j_{\text {corr }}$ versus $1 / T$ for $0.51 \mathrm{~mol} \mathrm{dm}^{-3}$ $\mathrm{NaCl}$ solution with and without inhibitor is presented in Fig. 5.

Obtained straight lines have slope $\left(-E_{\mathrm{a}} / R\right)$ from which the values of activation energy were calculated: $23.69 \mathrm{~kJ} \mathrm{~mol}^{-1}$ in the inhibitor-free solution, and $36.18 \mathrm{~kJ} \mathrm{~mol}^{-1}$ in the presence of inhibitor. The higher value of $E_{\mathrm{a}}$ in the presence of inhibitor indicates physical adsorption of propolis on the copper surface ${ }^{5,15,23}$.

\begin{tabular}{|c|c|c|c|c|c|}
\hline$C\left[\mathrm{mg} \mathrm{dm}^{-3}\right]$ & $E_{\text {corr }}[\mathrm{V}]$ & $j_{\text {corr }}\left[\mu \mathrm{A} \mathrm{cm}^{-2}\right]$ & $b_{\mathrm{a}}\left[\mathrm{V} \mathrm{dec}{ }^{-1}\right]$ & $b_{\mathrm{k}}\left[\mathrm{V} \mathrm{dec}{ }^{-1}\right]$ & $\eta[\%]$ \\
\hline \multicolumn{6}{|c|}{$T=25^{\circ} \mathrm{C}$} \\
\hline 0 & -0.246 & 30.25 & 0.070 & -0.125 & - \\
\hline 350 & -0.214 & 17.18 & 0.056 & -0.106 & 43.21 \\
\hline 1500 & -0.243 & 12.97 & 0.061 & -0.075 & 57.12 \\
\hline 2500 & -0.236 & 11.75 & 0.051 & -0.054 & 61.15 \\
\hline 3500 & -0.276 & 7.78 & 0.066 & -0.080 & 74.28 \\
\hline coating & -0.137 & 0.44 & 0.071 & -0.055 & 98.54 \\
\hline \multicolumn{6}{|c|}{$T=35^{\circ} \mathrm{C}$} \\
\hline 0 & -0.258 & 42.35 & 0.065 & -0.120 & - \\
\hline 3500 & -0.283 & 12.89 & 0.054 & -0.090 & 69.56 \\
\hline \multicolumn{6}{|c|}{$T=45^{\circ} \mathrm{C}$} \\
\hline 0 & -0.263 & 53.85 & 0.062 & -0.123 & - \\
\hline 3500 & -0.292 & 19.75 & 0.056 & -0.105 & 63.33 \\
\hline \multicolumn{6}{|c|}{$T=55^{\circ} \mathrm{C}$} \\
\hline 0 & -0.261 & 75.38 & 0.006 & -0.130 & - \\
\hline 3500 & -0.295 & 32.56 & 0.056 & -0.120 & 56.81 \\
\hline
\end{tabular}

Table 2 - Corrosion parameters and inhibition efficiency for copper in $0.51 \mathrm{~mol} \mathrm{dm^{-3 }} \mathrm{NaCl}$ solution in the absence and presence of propolis extract at different temperatures 


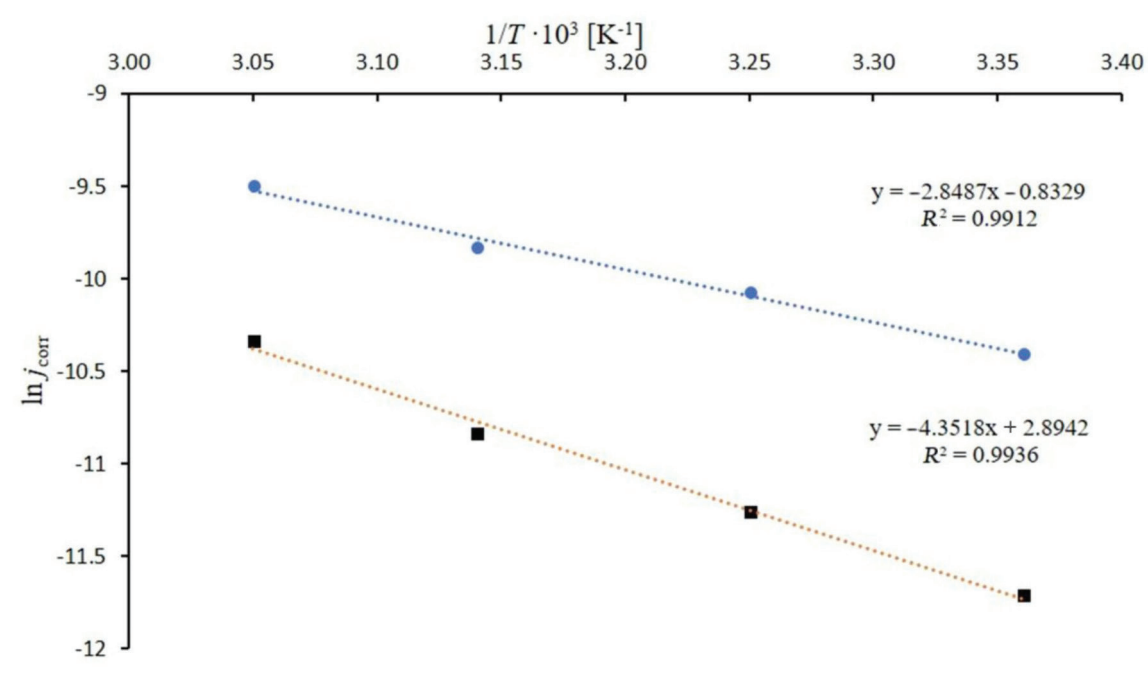

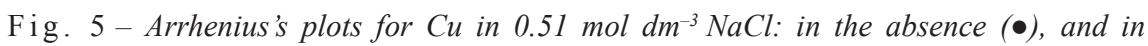
presence of propolis extract (-) in concentration of $3500 \mathrm{mg} \mathrm{dm}^{-3}$

\section{UV-visible spectroscopy}

Inhibition of corrosion of copper in $\mathrm{NaCl}$ solution by propolis was explained by mechanism of molecular adsorption, and confirmed by UV spectroscopy (Fig. 6). Spectra, which were obtained in the propolis solution before and after immersion of copper samples, have the same position of absorption maximum, with noticeable change in absorbance value. The change in the position of absorption maximum or change in the value of absorbance indicate the formation of a complex between two species in solution ${ }^{24,25}$. On the basis of the change in the value of absorbance, it can be concluded that organic compounds, in the propolis composition, were adsorbed on the copper surface and formed a protective film of inhibitor. This conclusion is in accordance with the increase in coverage degree with increasing propolis extract concentration, which was confirmed by electrochemical methods.

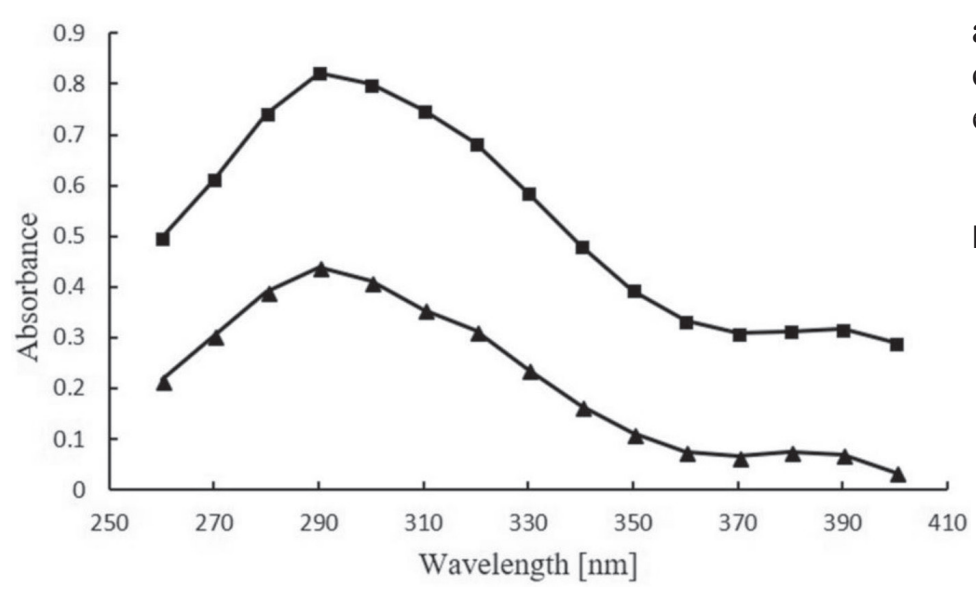

Fig. $6-U V$-Visible spectra of test solution with propolis extract (3500 $\left.\mathrm{mg} \mathrm{dm}^{-3}\right)$ : before immersion (๘), and after 48 hours immersion ( $\mathbf{\Delta})$ of copper samples in solution

\section{Conclusion}

The results confirmed that propolis can be used as a corrosion inhibitor for copper in $\mathrm{NaCl}$ solution. Thus, it can be concluded that inhibition efficiency of propolis increases with its concentration, and the highest efficiency was achieved with propolis coating on the electrode surface. Based on the change in corrosion potential in the presence of inhibitor as compared to the corrosion potential in $\mathrm{NaCl}$ solution without inhibitor, propolis can be classified as a corrosion inhibitor of mixed type. Inhibitory action of propolis was explained by mechanism of adsorption in accordance with Langmuir's isotherm. The value of free adsorption energy indicates the spontaneity of adsorption process, which has character of physical adsorption. Addition of propolis increases activation energy of the adsorption process, indicating physical adsorption. The results of UV-VIS spectroscopy confirm the conclusion about adsorption of organic compounds of propolis on copper surface. Propolis can be used as an eco-friendly inhibitor of copper corrosion.

\section{References}

1. Al Kharafi, F. M., Al-Awadi, N. A., Ghayad, I. M., Abdullah, R. M., Ibrahim, M. R., Corrosion protection of copper using azoles applied on its surface at high temperature under vacuum, Int. J. Electrochem. Sci. 6 (2011) 1562.

2. Sherif, El-Sayed M., Effects of 2-amino-5-(ethylthio)-1,3,4-thiadiazole on copper corrosion as a corrosion inhibitor in $3 \% \mathrm{NaCl}$ solutions, Appl. Sur. Sci. 252 (2006) 8615 .

doi: https://doi.org/10.1016/j.apsusc.2005.11.082

3. Sherif, El-Sayed M., Erasmus, R. M., Comins, J. D., Corrosion of copper in aerated acidic pickling solutions and its 
inhibition by 3-amino-1,2,4-triazole-5-thiol, J. Colloid \& Inter. Sci. 306 (2007) 96 doi: https://doi.org/10.1016/j.jcis.2006.10.029

4. Raja, P. B., Sethuraman, M. G., Natural products as corrosion inhibitor for metals in corrosive media - A review, Mater. Lett. 62 (2008) 113. doi: https://doi.org/10.1016/j.matlet.2007.04.079

5. Gapsari, F., Soenoko, R., Suprapto, A., Suprapto, W., Bee wax propolis extract as eco-friendly corrosion inhibitors for 304SS in sulfuric acid, Int. J. Corros. 2015 (2015) 1. doi: https://doi.org/10.1155/2015/567202

6. Fouda, A. S., Hamdy Badr, A., Aqueous extract of propolis as corrosion inhibitor for carbon steel in aqueous solutions, Afr. J. Pure Appl. Chem. 7 (2013) 350. doi: https://doi.org/10.5897/AJPAC2013.0524

7. Dolabella, L. M. P., Oliveira, J. G., Lins, V., Matencio, T., Vasconcelos, W. L., Ethanol extract of propolis as a protective coating for mild steel in chloride media, J. Coat. Technol. Res. 13 (2016) 543 doi: https://doi.org/10.1007/s11998-015-9765-1

8. Varvaraa, S., Bostan, R., Bobis, O., Gaina, L., Popa, F., Mena, V., Souto, R. M., Propolis as a green corrosion inhibitor for bronze in weakly acidic solution, App. Sur. Sci. $\mathbf{4 2 6}$ (2017) 1100. doi: https://doi.org/10.1016/j.apsusc.2017.07.230

9. Burdock, G. A., Review of the biological properties and toxicity of bee propolis (Propolis), Food Chem. Toxicol. 36 (1998) 347. doi: https://doi.org/10.1016/S0278-6915(97)00145-2

10. Rebiai, A., Lanez, T., Belfar, M. L., In vitro evaluation of antioxidant capacity of algerian propolis by spectrophotometrical and electrochemical assays, Int. J. Pharm. 7 (2011) 113. doi: https://doi.org/10.3923/ijp.2011.113.118

11. Oguzie, E. E., Li, Y., Wang, F. H., Effect of 2-amino-3-mercaptopropanoic acid (cysteine) on the corrosion behaviour of low carbon steel in sulphuric acid, Electrochim. Acta $\mathbf{5 3}$ (2007) 909 .

doi: https://doi.org/10.1016/j.electacta.2007.07.076

12. Haleem, A. E. S. M., Aal, A. E. E. E., Atia, A. M., Behaviour of the copper electrode in alkaline-sulfide solutions under natural corrosion conditions, Corrrosion 61(9) (2005) 838. doi: https://doi.org/10.5006/1.3280653

13. Ferreira, E. S., Giancomelli, C., Giacomelli, F. C., Spinelli, $A$., Evaluation of the inhibitor effect of L-ascorbic acid on the corrosion of mild steel, Mater. Chem. Phys. 83 (2004) 129. doi: https://doi.org/10.1016/j.matchemphys.2003.09.020

14. Li, W., He, Q., Zhang, S., Pei, C., Hou, B., Some new triazole derivatives as inhibitors for mild steel corrosion in acidic medium, J. Appl. Electrochem. 38 (2008) 289. doi: https://doi.org/10.1007/s10800-007-9437-7
15. Zarrouk, A., Warad, I., Hammouti, B., Dafali, A., Al-Deyab, $S$. S., Benchat, $N$., The effect of temperature on the corrosion of $\mathrm{Cu} / \mathrm{HNO}_{3}$ in the presence of organic inhibitor: Part2, Int. J. Electrochem. Sci. 5 (2010) 1516.

16. Mora, N., Cano, E., Polo, J. L., Puente, J. M., Bastidas, J. $M$., Corrosion protection properties of cerium layers formed on tinplate, Corros. Sci. 46 (2004) 563. doi: https://doi.org/10.1016/S0010-938X(03)00171-9

17. Ali, S. A., Saeed, G. T., Rahman, U. S., The isoxazolidines: A new class of corrosion inhibitors of mild steel in acidic medium, Corros. Sci. 45 (2003) 253. doi: https://doi.org/10.1016/S0010-938X(02)00099-9

18. Li, X., Xie, X., Deng, S., Du, G., Two phenylpyrimidine derivatives as new corrosion inhibitors for cold rolled steel in hydrochloric acid solution, Corros. Sci. 87 (2014) 27. doi: https://doi.org/10.1016/j.corsci.2014.05.017

19. Mihit, M., El Issami, S., Bouklah, M., Bazzi, L., Hammouti, $B$., The inhibited effect of some tetrazolic compounds towards the corrosion of brass in nitric acid solution, Appl. Surf. Sci. 252 (2006) 2389. doi: https://doi.org/10.1016/j.apsusc.2005.04.009

20. Branzoi, V., Branzoi, F., Baibarac, M., The inhibition of the corrosion of Armco iron in $\mathrm{HCl}$ solutions in the presence of surfactants of the type of $\mathrm{N}$-alkyl quaternary ammonium salts, Mater. Chem. Phys. 65 (2000) 288. doi: https://doi.org/10.1016/S0254-0584(00)00260-1

21. Zhou, Y., Zhang, S., Guo, L., Xu, S., Lu, H., Gao, F., Studies on the effect of a newly synthesized schiff base compound on the corrosion of copper in $3 \% \mathrm{NaCl}$ solution, Int. J. Electrochem. Sci. 10 (2015) 2072.

22. Zhang, Q. B., Hua, Y. X., Corrosion inhibition of aluminum in hydrochloric acid solution by alkylimidazolium ionic liquids, Mater. Chem. Phys. 119 (2010) 57. doi: https://doi.org/10.1016/j.matchemphys.2009.07.035

23. Oguzie, E. E., Adindu, C. B., Enenebeaku, C. K., Ogukwe, C. E., Chidiebere, M. A., Oguzie, K. L., Natural products for materials protection: Mechanism of corrosion inhibition of mild steel by acid extracts of Piper guineense, J. Phys. Chem. 116 (2012) 13603. doi: https://doi.org/10.1021/jp300791s

24. Singh, A., Ebenso, E. E., Quraishi, M. A., Theoretical and electrochemical studies of Cuminum cyminum (Jeera) extract as green corrosion inhibitor for mild steel in hydrochloric acid solution, Int. J. Electrochem. Sci. 7 (2011) 8543

25. Choudhary, G., Sharma, Ar., Monika, Banger, R. K., Sharma, A., Combating acid corrosion of AA6063 by Euphorbia hirta weed extract, Ind. J. Sci. Res. and Tech. 3(6) (2015) 12. 